\title{
Utilização de enxerto ósseo autógeno na reabilitação dos maxilares
}

\author{
Use of autogenous bone graft in the rehabilitation of the jaws
}

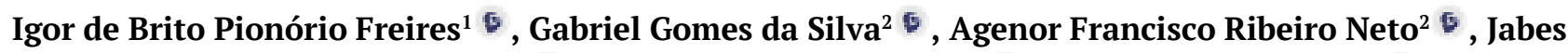 \\ Gennedyr da Cruz Lima ${ }^{2}$, Juliana Campos Pinheiro ${ }^{2^{*}}{ }^{G}$, Bruno Torres Bezerra ${ }^{16}$
}

${ }^{1}$ Universidade Tiradentes, Aracaju, Sergipe, Brasil. ${ }^{2}$ Centro de Biociências, Universidade Federal do Rio Grande do Norte, Natal, Rio
Grande do Norte, Brasil. *Autor para correspondência. E-mail: julianapinheiroodonto92@gmail.com

Resumo: Introdução: O processo de perda de tecido ósseo pode ocorrer por diversos fatores, causando no paciente problemas funcionais, estéticos e psicológicos, dificultando o tratamento reabilitador utilizando próteses dentarias. Nesse contexto, o presente artigo tem como objetivo realizar uma revisão científica da literatura, apontando as vantagens e desvantagens do enxerto ósseo autógeno, elucidando as principais indicações para a odontologia. Revisão: A recuperação de áreas edêntulas utilizando os enxertos ósseos autógenos exibe um importante papel na odontologia, proporcionando um prognóstico adequado para o paciente, desde que o tratamento esteja bem elaborado dentro das condições ideais de quantidade e qualidade óssea. As áreas doadoras intra-orais são constituídas pela sínfise mentoniana, ramo e tuberosidade da maxila. Já a calota craniana, crista ilíaca, costelas, tíbia e fíbula constituem as áreas doadoras extra-orais. As áreas doadoras intra-orais exibem boas propriedades biológicas na reconstrução de pequenos e médios defeitos ósseos, correspondente a aproximadamente quatro unidades dentais. Em casos de regenerações ósseas extensas, são indicadas a utilização de áreas doadoras extra-orais, sendo a crista ilíaca a mais comumente utilizada, devido a boa quantidade óssea que a mesma oferece. Considerações finais: A utilização do enxerto autógeno apresenta como vantagens a sua excelente biocompatibilidade entre a área doadora e a receptora, possibilitando a realização das técnicas regenerativas ósseas em consultório odontológico com a utilização de anestesia local, exibindo um baixo custo e alto nível de aceitação estética para o paciente. Entretanto, em defeitos extensos a cirurgia deve ser realizada em ambiente hospitalar sob anestesia geral com uma equipe multidisciplinar, apresentando um custo elevado.

Palavras-chave: enxerto ósseo autógeno, substitutos ósseos, reabilitação oral.

\begin{abstract}
Introduction: The bone tissue loss process can occur due to several factors, causing functional, aesthetic and psychological problems in the patient, making rehabilitation treatment difficult using dental prostheses. In this context, this article aims to conduct a scientific review of the literature, pointing out the advantages and disadvantages of autogenous bone grafts, elucidating the main indications for dentistry. Review: The recovery of edentulous areas using autogenous bone grafts plays an important role in dentistry, providing an adequate prognosis for the patient, as long as the treatment is well elaborated within the ideal conditions of bone quantity and quality. The intraoral donor areas are made up of the mentonian symphysis, branch and maxillary tuberosity. The skull cap, iliac crest, ribs, tibia and fibula are the extra-oral donor areas. The intraoral donor areas exhibit good biological properties in the reconstruction of small and medium bone defects, corresponding to approximately four dental units. In cases of extensive bone regeneration, the use of extra-oral donor areas is indicated, with the iliac crest being the most commonly used, due to the good bone quantity it offers. Final Remarks: The use of autogenous graft has the advantages of its excellent biocompatibility between the donor and recipient areas, enabling bone regeneration techniques to be performed in a dental office with the use of local anesthesia, showing a low cost and a high level of aesthetic acceptance for the patient. However, in extensive defects, surgery should be performed in a hospital environment under general anesthesia with a multidisciplinary team, presenting a high cost.
\end{abstract}

Keywords: autogenous bone graft, bones substitutes, oral rehabilitation.

\section{Introdução}

O tecido ósseo é uma estrutura especializada e altamente vascularizada possuindo uma excelente capacidade regenerativa. Entretanto, dependendo do tipo e do tamanho do defeito ósseo, o mesmo não se 
regenera por completo necessitando de terapias adicionais. A perda óssea pode ocorrer por fatores associados a extração dentária, processos infecciosos, traumas, neoplasias e distúrbios de desenvolvimento. A presença do edentulismo está associada a danos funcionais, estéticos e psicológicos em pacientes que necessitam de reabilitação oral (Azevedo et al., 2015). No entanto, a ocorrência da reabsorção do tecido ósseo ocasiona a perda da dimensão vertical e horizontal, comprometendo o tratamento do paciente, através da utilização de próteses dentárias (Mendonça et al., 2015). As técnicas de regeneração óssea guiada, tem como objetivo corrigir os defeitos ósseos, através da utilização de enxertos (Pessoa et al., 2015). O enxerto ósseo é classificado de acordo com sua origem, sendo ele, autógeno, quando retirado do próprio indivíduo, homólogo, quando doado por um indivíduo da mesma espécie, xenógeno, quando removido de um indivíduo de outra espécie (de origem animal) e aloplástico, quando produzido sinteticamente por biomateriais específicos (Pessoa et al., 2015).

Para ser considerado um enxerto ósseo ideal, o mesmo deve apresentar uma boa capacidade osteogênica, osteoindura e osteocondutora, assim como não deve proporcionar uma resposta auto-imune no indivíduo. Outras características consideradas promissoras para o sucesso do tratamento é a presença de uma boa quantidade e qualidade de tecido ósseo formado no local (Pereira et al., 2012). O enxerto autógeno apresenta características biológicas ideais para o tratamento regenerativo, devido a biocompatibilidade que ocorre entre o leito doador e receptor do paciente. Dentre as vantagens observadas, desacatam-se a presença de uma rápida osteocondução, osteogênese e revascularização no local, diminuindo desta forma o risco de infecções. Contudo essa modalidade de tratamento apresenta algumas desvantagens relacionadas a morbidade póscirúrgica do sitio doador, expondo o paciente a uma cirurgia de maior complexidade (Pereira et al., 2012).

A escolha do sítio doador deve levar em consideração os aspectos locais e sistêmicos do paciente, a qualidade e quantidade óssea necessária para o procedimento cirúrgico e o tipo e tamanho do defeito a ser tratado, devendo-se levar em consideração também o nível de dificuldade de acesso ao leito doador (Moraes et al., 2015). Os enxertos autógenos podem ser obtidos de diferentes regiões do corpo, sendo a crista do osso ilíaco, a calota craniana, a tíbia, as costelas e a região de ramo e sínfise da mandíbula, as áreas doadoras mais utilizadas no tratamento regenerativo dos ossos maxilares (Moraes et al., 2015). Nesse contexto, o presente artigo tem como objetivo realizar uma revisão cientifica da literatura, apontando as vantagens e desvantagens do enxerto ósseo autógeno, elucidando as principais indicações para a odontologia.

\section{Revisão}

O enxerto ósseo autógeno exibe uma boa incorporação no leito receptor, apresentando uma baixa reabsorção pós-cirúrgica, mantendo desta forma, o volume ósseo desejado no local. No tratamento regenerativo dos diferentes tipos de defeitos ósseos, busca-se utilizar os sítios doadores intra-orais de fácil acesso, que apresentem uma boa proximidade entre o leito doador e receptor. A sínfise mentoniana é considerada uma região doadora bastante promissora, possibilitando a remoção do tecido ósseo na forma de bloco corticomedular, e apresentando um menor potencial de reabsorção óssea (Mendonça et al., 2015).

A região anterior da mandíbula é uma área doadora utilizada para promover pequenas e médias reconstruções ósseas. A literatura relata que as áreas enxertadas com o tecido ósseo proveniente da sínfise, exibem melhores resultados associados ao ganho em altura e largura para a reconstrução de defeitos alveolares onde serão instalados os implantes osseointegrados (Freitas et al., 2012). Contudo, a remoção de enxertos da sínfise, não é recomendada como primeira escolha nos procedimentos de enxertia, devido aos altos índices de complicações pós-operatórias, como a presença de parestesia temporária ou permanente dos tecidos moles e dentes anteriores, ocasionada pela lesão do nervo mentual (Mendonça et al., 2015).

A região da tuberosidade da maxila é uma área doadora constituída por um tecido ósseo esponjoso, podendo oferecer pequenas e medias quantidades de tecido na forma particulada (Rodrigues et al., 2015). Esta região apresenta um baixo índice complicações pós e trans-operatória, exibindo um fácil acesso. Todavia, a quantidade e qualidade do tecido ósseo dessa região são menores quando comparadas com as áreas mandibulares (Rocha et al., 2015). Dentre as vantagens observadas, ressalta-se a possibilidade da realização do procedimento cirúrgico em consultório odontológico sobre anestesia local (Rocha et al., 2015). A região proporciona uma boa quantidade para a realização de pequenos aumentos no rebordo alveolar. Devido a sua natureza esponjosa, recomenda-se a utilização de membranas biológicas para estabilizar o enxerto ósseo no leito receptor (Rodrigues et al., 2015).

A região do ramo mandibular possui um tecido ósseo predominantemente cortical, oferecendo uma quantidade adequada de enxerto para a regeneração óssea. A retirada do enxerto dessa região fornece um 
volume ósseo para uma área correspondente a três ou quatro elementos dentários. Deve-se ressaltar que a medida que aumenta o tamanho do enxerto a ser removido, maior é a possibilidade da ocorrência de complicações (Rocha et al., 2015). As principais complicações são a fratura mandibular, lesão do feixe vasculo nervoso e deiscência da sutura, podendo ainda ocorrer reabsorção, mobilização do enxerto e a não integração do mesmo (Pereira et al., 2012). Os riscos e complicações cirúrgicas associados a utilização dos enxertos ósseos autógenos provenientes da região intra-oral estão relacionados aos possíveis comprometimentos dos elementos dentários remanescentes, assim como a ocorrência de necrose tecidual (Freitas et al., 2012). A literatura aponta que o ramo da mandíbula exibe uma menor morbilidade pós-operatória, possibilitando a remoção de um enxerto com volume e densidade óssea suficiente (El-Ghareeb et al., 2012).

A presença de tumores e traumatismos graves na região de cabeça e pescoço, assim como as reabsorções ósseas ocasionadas pela ausência dentária, podem comprometer a anatomia dos ossos maxilares, exigindo desta forma uma extensa regeneração óssea do local. As áreas doadoras extra-orais, são utilizadas para favorecer uma maior quantidade de enxertos ósseos (Lisboa et al., 2012). A calota craniana é uma área doadora extra-oral constituída pelos ossos parietais e o occipital, que exibem uma semelhança da sua origem embrionária intramembranosa com o sitio receptor das regiões maxilo-mandibulares (Lisboa et al., 2012). O enxerto obtido da calota craniana é uma alternativa viável para as reconstruções de maxilas atróficas, fornecendo uma grande quantidade de osso cortical, estabilizando desta forma o bloco de enxertia no local. Este tipo de enxerto tem como vantagens a presença de um baixo índice de reabsorção e uma menor morbidade pós-operatória, possibilitando de remoção de vários blocos ósseos em um mesmo tempo cirúrgico (Azevedo et al., 2015). Na odontologia, suas principais indicações estão relacionadas a reconstrução de extensas perdas ósseas com a finalidade de reabilitar o local utilizando os implantes dentários (Azevedo et al., 2015). Entretanto, esse tipo de enxerto apresenta desvantagens, associadas as possibilidades de ocorrência de lesões intracranianas, hematoma subdural por hemorragia, maior tempo cirúrgico, e um maior custo para o paciente (Azevedo et al., 2015).

Para se obter uma grande quantidade de tecido ósseo cortico-trabecular em extensas reconstruções dos ossos maxilares para uma futura reabilitação com implantes, deve-se utilizar sítios doadores extra-oral como a crista ilíaca, que apresenta uma boa quantidade e qualidade óssea para enxertia (Rodrigues et al., 2015). Contudo, algumas limitações podem ser observadas neste tipo de procedimento. Dentre as desvantagens, destacam-se a presença de uma cicatriz cutânea e dor pós-operatória, assim como o risco da ocorrência de uma parestesia temporária ou permanente, lesão do nervo cutâneo, perfuração peritoneal e fraturas. Pacientes que se encontram em fase de desenvolvimento puberal não devem realizar este tipo de cirurgia devido possibilidade de alteração no padrão de crescimento das mesmas (Molon et al., 2015).

A principal indicação da utilização do tecido ósseo proveniente da costela na odontologia, está relacionada a reconstrução da articulação têmporo-mandibular, que possui um tecido ósseo predominantemente cortical e pouco tecido trabeculado (Rodrigues et al., 2015). Entretanto, o formato e contorno deste tipo de enxerto são menos satisfatórios apresentando um alto índice de reabsorção quando comparado com outros locais doadores autólogos (Freitas et al., 2012). A costela é um local doador menos favorável para reconstruções maxilo-mandibulares, exibindo um risco de morbidez pós-operatória alto, podendo ocasionar o dilaceramento da pleura durante o procedimento cirúrgico (Rodrigues et al., 2015). Na ocorrência de defeitos de médio e grande porte da cavidade oral e maxilofacial, pode-se utilizar enxertos autógenos obtidos da tíbia e fíbula. Estes tipos de enxertos extra-orais, oferecem grandes quantidades de osso esponjoso, favorecendo uma melhor cicatrização e recuperação do local.

As principais indicações para a utilização de enxertos obtidos da tíbia estão relacionadas a reconstrução de defeitos provenientes da crista alveolar e levantamentos dos seios maxilares (Lisboa et al., 2012). Entretanto, a sua coleta pode ocasionar uma parestesia temporária e presença de uma cicatriz cirúrgica. Este tipo de cirurgia não deve ser realizado em pacientes jovens, devido ao risco de prejuízos no desenvolvimento da epífise (Lisboa et al., 2012). A fíbula é uma área doadora que fornece uma grande quantidade de tecido ósseo cortical para as reconstruções maxilo-mandibulares, exibindo uma menor morbidade do sítio doador e não interferindo no crescimento de pacientes em desenvolvimento puberal (Peterson, 2000). O enxerto ósseo vascularizado da fíbula tem sido utilizado com frequência no tratamento de extensas perdas ósseas decorrentes de causas pós-traumáticas, tumorais e infecciosas. Contudo, este tipo de procedimento possui limitações em relação a obtenção de ganho ósseo em altura da crista alveolar, devendo ser avaliada individualmente cada situação (Chen et al, 2005). 


\section{Discussão}

Os enxertos de origem autógena apresentam uma melhor previsibilidade em procedimentos reconstrutivos devido as suas propriedades osteogênicas, osteocondutoras e osteoindutoras (Moraes et al., 2015). Segundo Milhomem (2014) e Ersanli et al. (2016) observaram que a utilização de enxertos provenientes da região da sínfise e do ramo mandibular, apresentaram melhores ganhos em volume de tecido ósseo, exibindo um menor índice de complicações pós-operatória. Freitas et al. (2012), Pereira et al. (2012), Rodrigues et al. (2015) e Rocha et al. (2015) relataram que não é possível conseguir ganhos iguais entre a região da sínfise e do ramo mandibular, pois o limite de remoção do tecido na região do ramo é menor e a tentativa de igualá-las aumentaria o risco de fratura mandibular e lesão no feixe vasculo-nervoso na região. Rocha et. al. (2015) realizaram 103 procedimentos de remoção de tecido ósseo das regiões intra-orais, sendo observado que o episódio de complicações e morbidade foi menor na área de tuberosidade da maxila quando comparadas as áreas mandibulares.

De acordo com Freitas et al. (2012), Mendonça et al. (2015) e Molon et al. (2015) a cavidade oral apresenta um tecido ósseo para enxertia com característica de osso cortical no ramo mandibular, e do tipo trabecular na sínfise. Em relação ao tipo cortico-trabecular, o mesmo pode ser observado na região do mento. Para Rodrigues et al. (2015) e Molon et al. (2015) a crista ilíaca é o local de escolha para a realização de grandes reconstruções nos ossos maxilares devido a sua grande quantidade de tecido ósseo disponível. Em sua parte interna, observa-se uma abundante quantidade de osso medular ricamente vascularizado e abundante em osteoblastos. Esses achados corroboram com o estudo de Molon et al. (2015), no qual os autores afirmaram que a crista ilíaca é o sitio doador de primeira escolha para as reconstruções alveolares extensas, devido a sua grande quantidade de células ósseas que auxiliam na osteogênese em curto prazo pós-enxertia.

Rodrigues et al. (2015) e Rocha et al. (2015) compararam os enxertos obtidos da calota craniana com os enxertos obtidos da crista ilíaca. Os enxertos provenientes da calota craniana apresentaram uma menor taxa de reabsorção e melhor qualidade estética. No entanto, segundo Azevedo et al. (2015) e Moraes et al. (2015) as desvantagens da utilização da calota craniana em relação com a crista ilíaca estão relacionadas ao tempo cirúrgico que é maior na calota craniana, pois geralmente a remoção do tecido ósseo não é feita junto com o preparo da área receptora, existindo a possibilidade da ocorrência de lesões intracranianas irreversíveis e dificuldade em aceitação por parte do paciente. De acordo com Mendonça et al. (2015) e Kokosis et al. (2016) em uma comparação relacionada aos riscos de morbidade e complicações pós-operatórias dos casos de enxerto da crista ilíaca com o da tíbia, observou-se que a cirurgia da crista ilíaca apresenta um acesso cirúrgico mais complexo, com estruturas anatômicas sujeitas a maiores riscos. Já os enxertos originados da tíbia apresentam riscos relativamente baixos, obtendo-se a mesma qualidade de osso cortico-esponjoso.

Lisboa et al. (2012), Rodrigues et al. (2015) e Rocha et al. (2015), mencionaram que a costela é uma região pouco utilizada para enxertia, devido ao seu baixo volume quando comparado com as demais áreas extraorais. Segundo Chen et al. (2005) o uso de retalho livre de fíbula requer uma criteriosa avaliação préoperatória, afim de investigar sinais de insuficiência vascular periférica, como atrofia cutânea, unhas hipertróficas, pulsos diminuídos ou estase venosa. Embora não faça parte da rotina, a arteriografia deve ser indicada, uma vez que a retirada dos vasos fibulares pode agravar quadros limítrofes. A técnica também é contra-indicada, se houver história de traumatismo com fratura no membro.

\section{Considerações finais}

A utilização do enxerto autógeno apresenta como vantagens a sua excelente biocompatibilidade entre a área doadora e a receptora, possibilitando a realização das técnicas regenerativas ósseas em consultório odontológico com a utilização de anestesia local, exibindo um baixo custo e alto nível de aceitação estética para o paciente. Entretanto, em defeitos extensos a cirurgia deve ser realizada em ambiente hospitalar sob anestesia geral com uma equipe multidisciplinar, apresentando um custo elevado.

\section{Referências}

Azevedo, E. T. D., Costa, D. L., Przysiezny, P. E., Furlong, M., Santos Junior, L. D., \& Romanini, É. D. S. 2015. Reconstrução de maxila atrófica com enxerto proveniente de calota craniana para posterior reabilitação com implantes dentários û relato de caso. Full Dentistry in Science, 6(23), 177-182. 
Chen, C. R., Wagner, J. C., Volkweis, M. R., Valente, D. S., Valente, D. S., Grandi, G., \& Gerhadt, E. 2005. Uso de retalho livre de fíbula no complexo bucomaxilo-facial: relato de dois casos. Revista de Cirurgia e Traumatologia Buco-Maxilo-Facial, 5(4), 23-30.

El-Ghareeb, M., Pi-Anfruns, J., Khosousi, M., Aghaloo, T., \& Moy, P. 2012. Nasal floor augmentation for the reconstruction of the atrophic maxilla: a case series. Journal of Oral and Maxillofacial Surgery, 70(3), e235-e241.

Ersanli, S., Arısan, V., \& Bedeloğlu, E. 2016. Evaluation of the autogenous bone block transfer for dental implant placement: Symphysal or ramus harvesting?. BMC Oral Health, 16(1), 4.

Freitas, J. A. D. S., Garib, D. G., Trindade-Suedam, I. K., Carvalho, R. M., Oliveira, T. M., Lauris, R. D. C. M. C., ... \& Mazzottini, R. 2012. Rehabilitative treatment of cleft lip and palate: experience of the Hospital for Rehabilitation of Craniofacial Anomalies-USP (HRAC-USP)-part 3: Oral and Maxillofacial Surgery. Journal of Applied Oral Science, 20(6), 673-679.

Kokosis, G., Schmitz, R., Powers, D. B., \& Erdmann, D. 2016. Mandibular reconstruction using the free vascularized fibula graft: an overview of different modifications. Archives of Plastic Surgery, 43(1), 3.

Lisbôa, E. I., Carneiro, E., Fariniuk, L. F., Westphalen, V. P. D., Inagaki, N. S., \& da Silva Neto, U. X. 2012. Enxerto autógeno e alterações pulpares. Revista da Faculdade de Odontologia-UPF, 17(2), 208-211

Mendonça, J. C. G., Masocatto, D. C., Oliveira, M. M., Jardim, E. C. G., kalife Coelho, T. M., Terra, G. A. P., ... $\&$ da Silva, J. C. L. 2015. Enxerto ósseo de mento estabilizado em pré-maxila e reabilitação com implantes osseointegrados: relato de caso. Archives of Health Investigation, 4(1), 13-19.

Milhomem, M. L. A. 2004. Enxertos autógenos intrabucais em implantodontia: Revisão de literatura. Revista Amazônia Science \& Health, 2(3), 32-37.

Molon, R. S. D., Paula, W. N. D., Spin-Neto, R., Verzola, M. H. A., Tosoni, G. M., Lia, R. C. C., \& Scaf, G. 2015. Correlation of fractal dimension with histomorphometry in maxillary sinus lifting using autogenous bone graft. Brazilian Dental Journal, 26(1), 11-18.

Moraes, P. H., Olate, S., Lauria, A., Asprino, L., de Moraes, M., \& de Albergaria-Barbosa, J. R. 2015. 8-10 year follow-up survival of dental implants in maxillae with or without autogenous bone graft reconstruction. International Journal of Clinical and Experimental Medicine, 8(10), 19282.

Pereira, C. C. S., Jardim, E. C. G., Carvalho, A. C. G. S., Gealh, W. C., Marão, H. F., Esper, H. R., \& Júnior, I. R. G. 2012. Técnica cirúrgica para obtenção de enxertos ósseos autógenos intrabucais em reconstruções maxilomandibulares. Revista de Cirurgia e Traumatologia Buco-Maxilo-Facial, 15(2), 83-9.

Pessoa, E. A. M., Braune, A., Casado, P. L., \& Tannure, P. N. (2017). Enxertos ósseos alveolares na fissura labiopalatina: protocolos atuais e perspectivas futuras. Revista de Odontologia da Universidade Cidade de São Paulo, 27(1), 49-55.

Peterson L. J. 2000. Cirurgia oral e maxilofacial contemporânea (3a ed.). Rio de Janeiro, RJ: Guanabara Koogan.

Rocha, J. F., Oliveira, J. C. S. D., Ramos, J. W. N., Araújo Filho, J. C. W. P. D., Gonçales, E. S., Hochuli-vieira, E., \& Carvalho, P. S. P. D. 2015. Enxerto ósseo mandibular, complicações associadas às áreas doadoras e receptoras, e sobrevivência de implantes dentários: um estudo retrospectivo. Revista de Odontologia da UNESP, 44(6), 340-344.

Rodrigues, R., Viana, B., Vieira, I., Tavares, J., Lobo, R., Portela, A., \& Vasconcelos, M. (2015). Dental stem cells characterization and bone regenerative potential in oral medicine. International Journal of Stem Cells, 2(1), 1 .

\section{Minicurrículo}

Igor de Brito Pionório Freires. Cirurgião-dentista graduado pela Universidade Tiradentes.

Gabriel Gomes da Silva. Graduação em Odontologia pela Universidade Federal do Rio Grande do NorteUFRN (andamento/ 2016-2021) e Aperfeiçoamento em Endodontia - Grupo Innovation (andamento 2019- 
2020). Atualmente, desenvolve o Projeto de Pesquisa intitulado: Análise clínicopatologica dos casos de linfangioma oral diagnosticados em um serviço de referência em patologia oral do nordeste brasileiro e os Projetos de extensão: Coordenador "Bolsista remunerado" do projeto Formando Sorrisos e Coordenador "Bolsista voluntário" do projeto Ateliê do Sorriso. Participante voluntário da Base de Pesquisa em Patologia Oral da UFRN.

Agenor Francisco Ribeiro Neto. Cirurgião-dentista graduado pela Universidade Federal do Rio Grande do Norte. Possui experiência no cuidado odontológico a pacientes nefropatas. Dedicação em estudos envolvendo predição e avaliação de risco para cárie dentária.

Jabes Gennedyr da Cruz Lima. Graduação em Odontologia pela Universidade Federal do Rio Grande do Norte- UFRN (/ 2015-2019). Desenvolveu o Projeto de Pesquisa intitulado: Validação do Índice Clínico de Queilite Actínica e participante nos Projetos de extensão: Projeto de Atendimento Odontológico aos Estudantes da UFRN e Ateliê do Sorriso. Participante voluntário da Liga Acadêmica de Odontopediatria-UFRN e participante bolsista da base de pesquisa de Patologia Oral-UFRN.

Juliana Campos Pinheiro. Cirurgiã-Dentista graduada pela Universidade Tiradentes. Mestre em Patologia Oral pela Universidade Federal do Rio Grande do Norte (UFRN); Doutorado em Ciências Odontológicas (andamento)- área de concentração: Biologia Experimental- UFRN (2018-2022); Membro da Sociedade Brasileira de Estomatologia e Patologia Oral (2016-atualmente)..

Bruno Torres Bezerra. Possui graduação em Odontologia pela Universidade Tiradentes (2005). Especialista e Mestre em Cirurgia e Traumatologia Buco-Maxilo-Facial pela Universidade do Grande Rio (UNIGRANRIO).Doutor em Ciências da Saúde pela Universidade Federal de Sergipe (UFS). Cirurgião BucoMaxilo-Facial do Hospital Primavera.Cirurgião Buco-Maxilo-Facial da Fundação Estadual de Saúde. Professor de Estomatologia e Traumatologia Universidade Tiradentes (UNIT). Professor de Cirurgia Oral e Implantes da ABO-SE.

Como citar: Freires, I.B.P., Silva, G.G., Ribeiro Neto, A.F., Lima, J.G.C., Pinheiro, J.C., \& Bezerra, B.T. 2020. Utilização de enxerto ósseo autógeno na reabilitação dos maxilares. Pubsaúde, 3, a051. DOI: https://dx.doi.org/10.31533/pubsaude3.a051

Recebido: 1 jul. 2020.

Revisado e aceito: 10 jul. 2020.

Conflito de interesse: os autores declaram, em relação aos produtos e companhias descritos nesse artigo, não ter interesses associativos, comerciais, de propriedade ou financeiros que representem conflito de interesse.

Licenciamento: Este artigo é publicado na modalidade Acesso Aberto sob a licença Creative Commons Atribuição 4.0 (CC-BY 4.0). 